23

\title{
Спектрофотометрическое определение форм присутствия йода в растворах соединений йода
}

\author{
() Н.Л. Алукер ${ }^{1}$, M. Herrmann ${ }^{2}$ \\ ${ }^{1}$ Кемеровский государственный университет, \\ 650000 Кемерово, Россия, \\ e-mail: naluker@gmail.com \\ ${ }^{2}$ Department of Meteorology and Atmospheric Science, The Pennsylvania State University, \\ 16802 PA, USA \\ e-mail: maria.herrmann@psu.edu
}

Поступила в редакцию 15.12.2020 г.

В окончательной редакции 29.01.2021 г.

Принята к публикации 05.02.2021 г.

Исследуются оптические характеристики растворов кристаллического йода и йодных соединений, определяются формы присутствия йода и некоторых сопутствующих соединений в растворах. Оценивается возможность применения прямых спектрофотометрических методов для определения различных форм нахождения йода и сопутствующих соединений в воде.

Ключевые слова: спектр поглощения, вода, йодид ион, йодат ион, трийодид ион, нитрат ион.

DOI: $10.21883 /$ OS.2021.05.50895.303-20

\section{Введение}

В природном йоде наряду с стабильным изотопом ${ }^{127} \mathrm{I}$ присутствует долгоживущий ${ }^{129} \mathrm{I}$ с большим периодом полураспада $\left(\sim 10^{7}\right.$ лет). При его распаде испускается бета-излучение с энергией $\sim 150 \mathrm{keV}$ и гамма-излучение с энергией $\sim 40 \mathrm{keV}$. В связи с большим периодом полураспада содержание ${ }^{129} \mathrm{I}$ нарабатывается в окружающей среде [1]. Короткоживущие изотопы йода $\left({ }^{131} \mathrm{I},{ }^{123} \mathrm{I},{ }^{124} \mathrm{I}\right.$, $\left.{ }^{125} \mathrm{I}\right)$ широко применяются в медицине, поэтому задача их детектирования важна [2]. Концентрация ${ }^{129} \mathrm{I}$ за счет деятельности предприятий ядерного комплекса может изменить существующее соотношение между стабильным и радиоактивным йодом в атмосфере, поэтому методы детектирования йода в объектах окружающей среды приобретают все большее значение. Трудность регистрации йода заключается в том, что он может присутствовать в соединениях, проявляя разные валентности (степени окисления). Это широко используется в аналитических йодометрических методиках определения ряда веществ [3].

При соединении с щелочными металлами йод образует соли, проявляя в этих устойчивых соединениях валентность -1 . Щелочные йодиды в кристаллическом состоянии являются модельными ионными системами и хорошо изучены. Ширина запрещенной зоны кристалла $\mathrm{KI}$ составляет $6.3 \mathrm{eV}$ [4]. Самый низкоэнергетический пик фундаментального поглощения $5.8 \mathrm{eV}$ связывают с созданием экситона [4]. В щелочных йодидах осуществляется локализация образующейся при облучении зоной дырки на двух ионах галогена, т.е. автолокализация дырки с образованием $V_{k}$-центра в виде $I_{2}^{-}$[4-5]. Йодиды металлов, например $\mathrm{CuI}, \mathrm{HgI}_{2}$, характеризуются сильной ионной связью, являются широкозонными полупроводниками с шириной зоны 3.1 и $2.13 \mathrm{eV}$ соответственно [6]. Они применяются в качестве полупроводниковых детекторов излучений, не требующих охлаждения при их использовании.

Кристаллический йод в свободном виде в природе не встречается, так как он очень легко переходит в газообразное состояние.

$\mathrm{B}$ атмосфере йод присутствует как $\mathrm{CH}_{3} \mathrm{I}, \mathrm{HIO}_{3}, \mathrm{ICN}$, $\mathrm{I}\left(\mathrm{NO}_{3}\right)_{3}$ и др. Основным процессом при фотовозбуждении молекулы свободного йода является диссоциация (прямой фотолиз, осуществляющийся при воздействии света с $\lambda<499 \mathrm{~nm}$ ) [7]. Основным резервуаром потребления атмосферного йода служит океан, но накапливается он в морских водорослях и почти полностью исчезает из морской воды, испаряясь под действием света. Из океана соединения йода снова попадают в атмосферу, поэтому йод обладает очень высокой миграционной способностью.

В воде йод частично гидрализуется в присутствии свободных ионов $\mathrm{H}^{+}$и $\mathrm{OH}^{-}: \mathrm{I}_{2}+\mathrm{H}_{2} \mathrm{O}=\mathrm{HI}+\mathrm{HIO}$, однако растворимость $\mathrm{I}_{2}$ в воде невелика и зависит от общей минерализации вод. Лучше он растворяется в спирте, сероуглероде и органических растворителях, а также в водных растворах йодидов, поэтому он может присутствовать в водах нефтяных и газовых месторождений в концентрациях, превышающих его ПДК в питьевой воде. В России именно подземные буровые воды являются основным источником получения йода. В природных водах йод может содержаться в виде ряда соединений. Это йодаты $\left(\mathrm{NaIO}_{3}\right)$, йодиды $(\mathrm{KI})$, гипойодиды $(\mathrm{KIO})$ йодноватая $\left(\mathrm{HIO}_{3}\right)$ и йодноватистая $(\mathrm{HIO})$ кислоты, йодистый метил $\left(\mathrm{CH}_{3} \mathrm{I}\right)$, трийодметан $\left(\mathrm{CHI}_{3}\right)$ и др. [8]. 
Йодиды щелочных металлов при больших концентрациях в растворах склонны образовывать полийодиды $\left(\mathrm{KI}_{3}\right)$. С кислородсодержащими растворителями йод образует соединения (выступая в качестве катиона с переменной валентностью) со слабыми донорно-акцепторными связями. Катион $\mathrm{I}^{+}$в свободном состоянии является нестабильным $[8,9]$, поэтому он в результате цепочки последовательных окислений окисляется до степени окисления +5 , в которой он присутствует в окружающей среде. Соединения семивалентного йода имеют меньшее значение.

Сорбированный на твердых носителях (например, кварце) йод образует комплексы с переносом заряда, что усиливает его связь с поверхностью [10].

ПДК йода в воде $125 \mu \mathrm{g} / \mathrm{dm}^{3}$, среднее содержания йода в природных водах $\sim 10 \mu \mathrm{g} / \mathrm{dm}^{3}$. Средние содержания йода в морской воде в виде йодидов 20-30 $\mathrm{g}$ на килограмм морской воды. При больших концентрациях йод является ядом, смертельная доза составляет 2-3 g.

С другой стороны, недостаток йода, являющегося структурным элементом синтеза гормонов щитовидной железы тироксина и трийодтиронина, приводит к развитию заболеваний щитовидной железы, т.е. поступление йода в организм в небольших концентрациях является необходимым [11].

В качестве метода детектирования низких содержаний йода в жидких средах рассматриваются оптические методы (люминесценция при лазерном возбуждении, спектрофотометрия) [12-17].

Однако, несмотря на многочисленность исследований, сохраняются вопросы при анализе спектров поглощения йода.

\section{Экспериментальная часть}

\section{Аппаратура и методика измерения}

Спектры поглощения измерялись с использованием спектрофотометра SHIMADZU UV-1700 и регистрировались с использованием кювет разных толщин: 20, 10, 2, $1 \mathrm{~mm}$.

Для исследований готовились растворы соединений йодидов и йодатов калия и лития, оксида йода и молекулярного йода в дистиллированной воде, природной нитрат-содержащей воде, ацетонитриле, спирте, этиленгликоле и гексане, а также паров йода, высаженных на кварцевое стекло. В качестве холостых (фоновых) проб использовались чистые растворители. Из спектров поглощения изучаемого соединения вычитался спектр поглощения растворителя. Измеренные спектры строились в координатах оптическая плотность $\left(\log \left(I_{0} / I\right)\right)$ при толщине поглощающего слоя $1 \mathrm{~cm}\left(\alpha, \mathrm{cm}^{-1}\right)-$ длина волны $(\mathrm{nm})$.

\section{Результаты исследования спектров поглощения водных растворов разных соединений йода}

В спектре поглощения растворов в воде йодидов щелочных металлов регистрируются две полосы поглощения: 6.39 (194 nm) и $5.49 \mathrm{eV}(226 \mathrm{~nm})$ (рис. 1).

Обе эти полосы поглощения $\mathrm{I}^{-}$, имеют близкие коэффициенты молярной экстинкции: 14200 и $134001 / \mathrm{mol} \mathrm{cm} \mathrm{[15].} \mathrm{Сильное} \mathrm{поглощение} \mathrm{позволяет} \mathrm{об-}$ наруживать ион $\mathrm{I}^{-}$в воде при концентрациях $\sim 30 \mu \mathrm{g} / \mathrm{l}$, т. е. ниже уровня ПДК. В достаточно широком диапазоне изменения концентрации раствора наблюдается линейная зависимость оптической плотности от концентрации (рис. $1, b)$. При больших концентрациях КІ в воде в спектре поглощения наблюдается слабая полоса поглощения с максимумом $\sim 350 \mathrm{~nm}$ и неявно выраженное поглощение в области $\sim 290 \mathrm{~nm}$, что свидетельствует о появлении в растворе $\mathrm{I}_{3}^{-}$.

Однако из-за возможного присутствия в измеряемых водах нитратов, нитритов, фенолов и других соединений, поглощающих в области спектра 185-235 nm, обнаружение йода при низких концентрациях становиться проблематичным. Так, в нитрат-содержащих природных водах (даже на уровне $\sim 1 \mathrm{mg} / \mathrm{l}$ ) на фоне сильного поглощения нитрат-иона с максимумом $202 \mathrm{~nm}$ и большой полушириной полосы поглощения йода на уровне ПДК $125 \mu \mathrm{g} / \mathrm{l}$ обнаружение йода будет невозможно [18]. Фенолы в природных водах не присутствуют в концентрациях, оказывающих влияние на спектр поглощения $\mathrm{I}^{-}$[19].

В сильно разбавленных водных растворах иодидов могут присутствовать соединения пятивалентного йода. Йодаты, к сожалению, не имеют характерных полос поглощения в УФ области спектра (рис. 2,a), однако наложение их УФ поглощения на поглощение иона $\mathrm{I}^{-}$ приводит к изменению соотношения полос 194 и $226 \mathrm{~nm}$ (рис. 2, $b$ ).

При растворении кристаллического йода в спектрах поглощения присутствуют полосы с максимумами поглощения $\mathrm{I}^{-}(194,226 \mathrm{~nm}), \mathrm{IO}_{3}^{-}(\leq 190 \mathrm{~nm})$, $\mathrm{I}_{3}^{-}(287-290 \mathrm{~nm}, 350-354 \mathrm{~nm})$ и поглощение комплекca $\left[\mathrm{I}_{2}-\mathrm{H}_{2} \mathrm{O}\right](\sim 460 \mathrm{~nm})$ [12-17]. Кроме этих полос в спектре (по разности) обнаруживается поглощение с максимумом $\sim 202 \mathrm{~nm}$, приписываемое поглощению $\mathrm{I}_{2}[12-17]$.

Полосы поглощения с максимумами 287 и $353 \mathrm{~nm}$ приписывают появлению в растворе трийодид-ионов $\mathrm{I}_{3}^{-}$[12-17]. Спиртовая настойка йода и растворы йода в органических растворителях содержат значительные количества трийодида: $\mathrm{I}_{2}+\mathrm{I}^{-} \rightleftharpoons \mathrm{I}_{3}^{-}$. В воде эффективность образования $\mathrm{I}_{3}^{-}$низкая, однако в силу высокого коэффициента молярной экстинкции он достаточно хорошо регистрируется в водном растворе йода. Растворение $\mathrm{I}_{2}$ в водном растворе с наличием иодидов щелочных металлов существенно повышает растворимость йода в воде и других полярных растворителях.

Спектры поглощения молекулярного йода в разных растворителях и паров йода, высаженных на кварцевое 

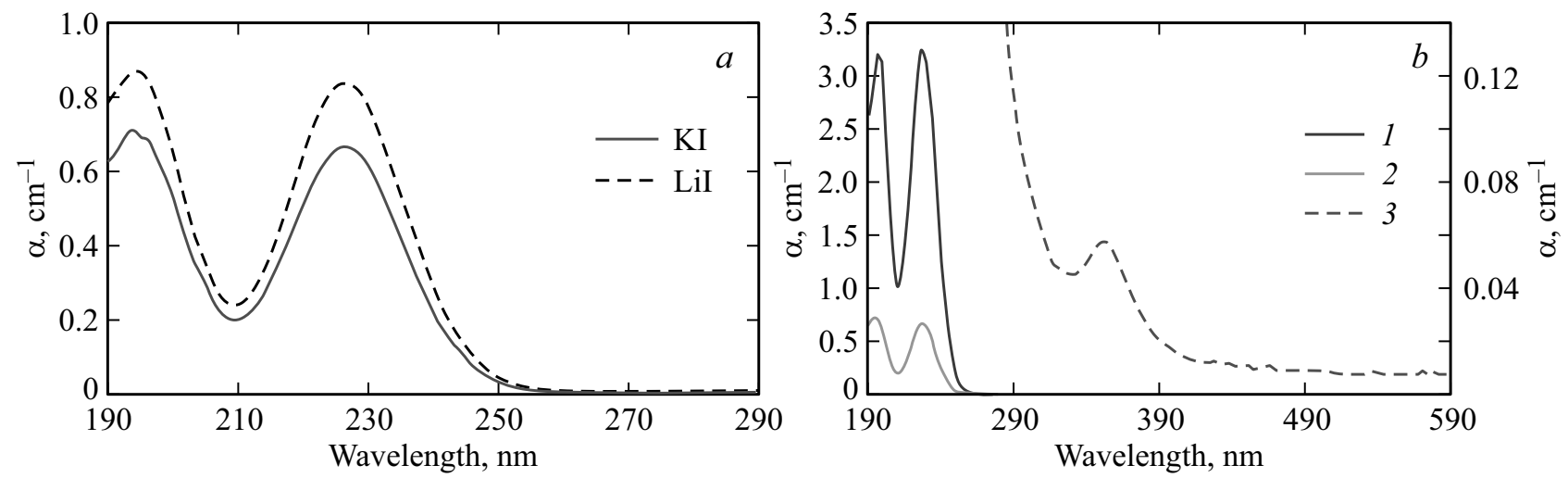

Рис. 1. (a) Спектры поглощения щелочных иодидов в воде. (b) Спектры поглощения КI в воде: $6 \mathrm{mg} / 1$ (кривая 1$)$, $30 \mathrm{mg} / 1$ (2), насыщенный раствор (3) (правая ось ординат).
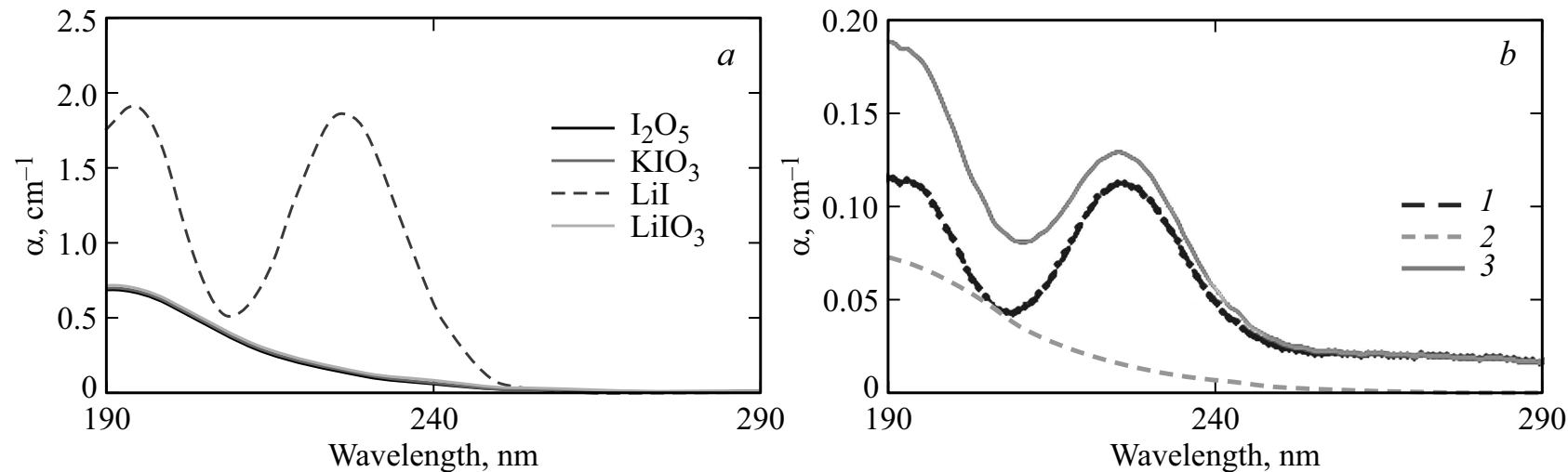

Pис. 2. (a) Спектры поглощения водных растворов соединений пятивалентного йода и LiI. (b) Влияние поглощения пятивалентного йода на перераспределение интенсивностей полос поглощения $\mathrm{I}^{-}: \mathrm{I}^{-}$(кривая 1$)$, $\mathrm{IO}_{3}^{-}(2)$, наблюдаемый спектр поглощения (3).

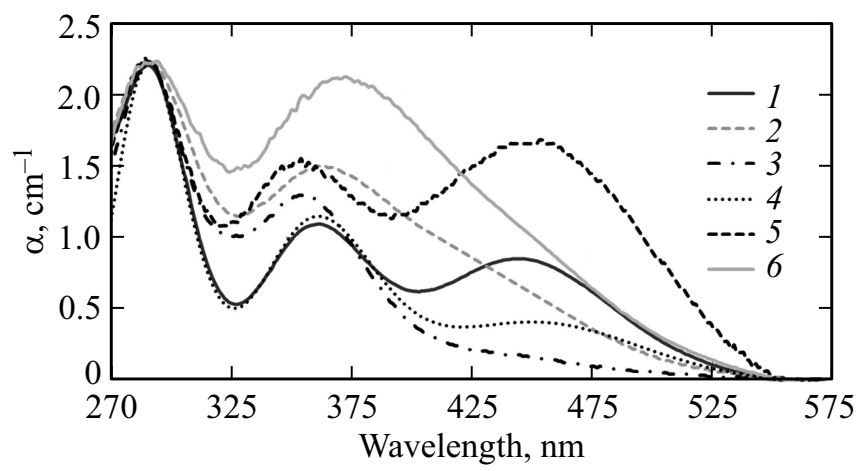

Рис. 3. Спектры поглощения растворов $\mathrm{I}_{2}$ в разных растворителях и $\mathrm{I}_{2}$ на кварцевом стекле, нормированные на поглощение $\mathrm{I}_{3}^{-}(290 \mathrm{~nm})$ : кривая 1 - ацетонитрил, 2 - спирт, 3 - вода, 4 - гексан, 5 - йод на кварцевом стекле, 6 - йод на кварцевом стекле.

стекло, нормированные на поглощение $\mathrm{I}_{3}^{-}(290 \mathrm{~nm})$, приведены на рис. 3. Концентрации вносимого в растворы йода на рис. 3 разные, так как в органических растворителях образование $\mathrm{I}_{3}^{-}$гораздо эффективнее, чем в водном растворе. Однако видно, что спектральные характеристики $\mathrm{I}_{3}^{-}$в разных растворителях почти не претерпевают изменений $(290 \mathrm{~nm}, \pi \leftrightarrow \pi ; 350 \mathrm{~nm}, n \leftrightarrow \sigma)$, поглощение в области $440-460 \mathrm{~nm}$, связываемое с поглощением комплекса (молекулярный йод-растворитель) довольно сильно меняется в зависимости от используемого растворителя, $n \leftrightarrow \pi$.

Даже незначительное поглощение в этой области свидетельствует о большом количестве связанного йода в силу низкого коэффициента молярной экстинкции комплекса.

Следовательно, для определения концентрации йода в растворе (и при низких, и при высоких его концентрациях в растворе) необходимо осуществлять детектирование четырех различных форм йода: $\mathrm{I}^{-}, \mathrm{I}_{3}^{-}, \mathrm{IO}_{3}^{-}$и комплекса $\mathrm{I}_{2}$-растворитель [12-17].

Спектр поглощения, полученный при растворении в дистиллированной воде паров йода, сорбированных на кварцевом стекле, т.е. перекристаллизованного (очищенного) молекулярного йода, приведен на рис. 4. В спектре поглощения выявляется поглощение $\mathrm{I}_{2}(460 \mathrm{~nm}), \mathrm{I}^{-}(194$ и $226 \mathrm{~nm}), \mathrm{I}_{3}^{-}(290$ и $350 \mathrm{~nm})$ и неявно выраженное поглощение $\mathrm{IO}_{3}^{-}(\sim 190 \mathrm{~nm})$. По 



Pис. 4. (a) Спектр поглощения высаженного на кварцевом стекле $\mathrm{I}_{2}$, растворенного в дистиллированной воде: 1 - измеренный спектр, 2 - выделенное поглощение $\mathrm{I}^{-}$(после вычитания поглощения $\mathrm{IO}_{3}^{-}$и $\mathrm{NO}_{3}^{-}$), 3 - измеренный спектр $(1)$ в увеличенном масштабе (правая шкала). (b) УФ часть того же спектра: 1 - измеренный спектр, 2 - эталонный спектр $\mathrm{NO}_{3}^{-}, 3-$ эталонный спектр $\mathrm{I}^{-}$, эталонный спектр $\mathrm{IO}_{3}^{-}, 4-$ спектр, восстановленный суммированием поглощения эталонных растворов $\mathrm{I}^{-}$, $\mathrm{IO}_{3}^{-}$и $\mathrm{NO}_{3}^{-}$в дистиллированной воде.
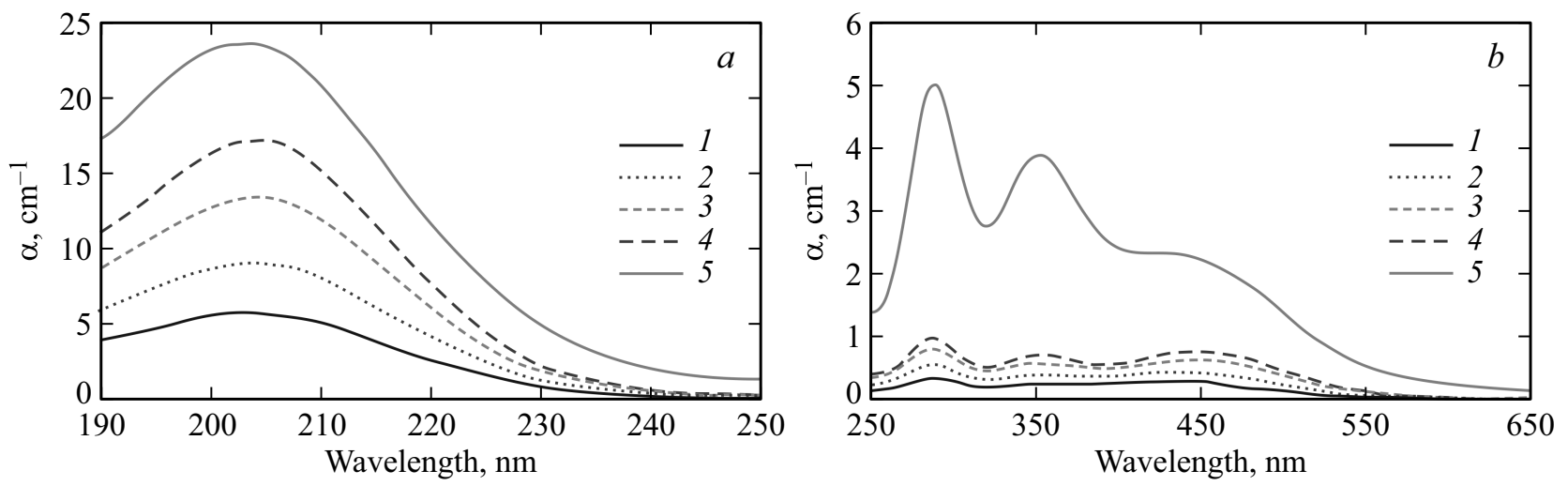

Рис. 5. (a) Спектр свежего насыщенного раствора $\mathrm{I}_{2}$ в дистиллированной воде, измеренный через определенное время после приготовления: $1-10 \mathrm{~min}, 2-15 \mathrm{~min}, 3-23 \mathrm{~min}, 4-30 \mathrm{~min}, 5-10000 \mathrm{~min}$. (b) Спектр свежего насыщенного раствора $\mathrm{I}_{2}$ в дистиллированной воде, измеренный через определенное время после приготовления: $1-10 \mathrm{~min}, 2-15 \mathrm{~min}, 3-23 \mathrm{~min}, 4-$ $30 \mathrm{~min}, 5-10000 \mathrm{~min}$.

разности спектров в УФ области кроме него выявляется поглощение в области $202 \mathrm{~nm}$.

Оценим концентрацию разных форм йода в растворе (рис. 4).

На основе коэффициентов молярной экстинкции полос 287 и $350 \mathrm{~nm}(36000$ и $20000 \mathrm{l} /(\mathrm{molcm}))$ можно оценить содержание $\mathrm{I}_{3}^{-}$в $0.80 \pm 0.05 \mathrm{mg} / \mathrm{l}$. Содержание $\mathrm{I}^{-}$на основе коэффициентов молярной экстинкции полос 194 и $226 \mathrm{~nm}(14200$ и 13400 1/( $\mathrm{mol} \mathrm{cm}))$ можно оценить в $7.0 \pm 0.5 \mathrm{mg} / \mathrm{l}$. Содержание $\mathrm{IO}_{3}^{-}$по поглощению $\sim 190 \mathrm{~nm}-$ в $2.0 \pm 0.5 \mathrm{mg} / 1$. Концентрацию нитрат-иона — в $5.0 \pm 0.2 \mathrm{mg} / \mathrm{l}$. Концентрация йода в комплексе с растворителем по поглощению $450 \mathrm{~nm}$ в $4.0 \pm 0.05 \mathrm{mg} / \mathrm{l}$.

При наблюдении в спектре всех полос поглощения большее количество йода будет сосредоточено в его комплексе с водой в виде иона $\mathrm{I}^{-}$, меньшее - в виде $\mathrm{I}_{3}^{-}$и в соединении с кислородом - в виде $\mathrm{IO}_{3}^{-}$.
Спектры поглощения насыщенного раствора кристаллического йода сразу после приготовления и спустя определенные промежутки времени после растворения показывают изменение концентраций соединений йода в растворе при его медленном растворении (рис. 5).

В УФ части спектра (рис. 5, a) выделяется полоса поглощения в области $202 \mathrm{~nm}$, приписываемая практически во всех литературных источниках поглощению $\mathrm{I}_{2}$ [12-17]. На наш взгляд, она обусловлена поглощением нитрат-иона [18]. В связи с тем, что это поглощение растет при растворении йода и насыщается через некоторое время после начала растворения йода, можно предположить, что на поверхности кристалликов йода присутствуют нитраты. Сорбция диоксида азота в присутствии влаги может приводить к образованию соединения йода с азотом $\left(\mathrm{I}\left(\mathrm{NO}_{3}\right)\right.$ или $\left.\mathrm{I}\left(\mathrm{NO}_{3}\right)_{3}\right)$, в котором йод имеет валентность +1 и +3 соответственно.

Щелочные металлы могут присутствовать на поверхности зерен кристаллического йода, образуя нитраты 
щелочных металлов $\left(\mathrm{MeNO}_{3}\right)$, растворимость которых в воде высокая.

Нарушение линейности роста поглощения в УФ полоce $202 \mathrm{~nm}$ (насыщение) происходит через $40 \mathrm{~min}$ после начала растворения, а полосы поглощения $\mathrm{I}_{3}^{-}$и $460 \mathrm{~nm}$ продолжают линейно расти в течение более длительного времени. Содержание нитрата в выдержанном насыщенном растворе молекулярного иона велико, и на его фоне поглощение $\mathrm{I}^{-}$зафиксировать не удается, хотя надежно фиксируются полосы поглощения $\mathrm{I}_{3}^{-}$и комплекса йода с растворителем.

Поглощение в области 280-360 nm, где наблюдается поглощение $\mathrm{I}_{3}^{-}$в воде, характерно для небольшого числа соединений. Из хорошо растворимых примесей это те же нитраты и нитриты, однако коэффициенты молярной экстинкции длинноволновых полос их поглощения малы, и они могут вносить вклад в поглощение растворов только при таких больших концентрациях, которые в природной воде практически не встречаются. Поэтому появление в спектре $\mathrm{I}_{3}^{-}$уже само по себе является сигналом к тому, что в растворе высокое содержание йода, так как в эту форму переходит при растворении в воде небольшая в процентном отношении часть йода.

Для получения насыщенного раствора в воду добавлялось не менее $3 \mathrm{~g}$ йода. Концентрация $\mathrm{NO}_{3}^{-}$при насыщении сигнала $150 \mathrm{mg} / 1$. Получается, что 5\% йода, вносимого в раствор, обогащено $\mathrm{NO}_{3}^{-}$, т.е. толщина поверхностного слоя, находящегося под воздействием азота, может составлять $\sim 50 \mu \mathrm{m}$ при размере кристалликов йода $\sim 1 \mathrm{~mm}$.

Оценим концентрации разных форм йода в насыщенном растворе после его длительной выдержки: $\sim 50 \pm 5 \mathrm{mg} / \mathrm{l} \mathrm{I}_{3}^{-}, \sim 200 \mathrm{mg} / \mathrm{l}$ комплекса, $\sim 150 \mathrm{mg} / \mathrm{l}$ нитрат-йона, не более $50 \mathrm{mg} / 1 \mathrm{I}^{-}$.

Таким образом, в насыщенном растворе и выдержанном в течение длительного времени растворе $\mathrm{I}_{2}$ в воде наибольшее количество йода будет сосредоточено в его комплексе с водой, а оставшийся йод находится в виде ионов $\mathrm{I}_{3}^{-}$и $\mathrm{I}^{-}$, с преимуществом трийодид-иона. Кроме йода в растворе присутствуют нитрат-ионы.

\section{Обсуждение}

Откуда же в растворе йода может появиться нитратион?

При воздействии на щелочно-галоидные кристаллы (ЩГК) радиационного и УФ облучения (в контакте с атмосферным воздухом) установленным является факт окисления поверхности кристалла. С ростом удельной поверхности глубина окисления увеличивается. Реакция идет через последовательное образование промежуточных продуктов при окислении $\mathrm{I}^{-}$до $\mathrm{I}^{5+}[20,21]$. В спектрах поглощения кристаллов КI в твердой фазе и в насыщенных растворах КІ наблюдается оптическое поглощение, характерное для $\mathrm{I}_{3}^{-}$[5]. Появление $\mathrm{IO}_{3}^{-}$ и $\mathrm{I}_{3}^{-}$на поверхности ЩГК обусловлено водой, всегда присутствующей на поверхности скола кристалла. Электронно-микроскопические исследования поверхности ЩГК, облученных рентгеновским и УФ излучением, демонстрируют также и то, что на их поверхности происходит образование кристаллических фаз размерами $\sim 300 \mathrm{~nm}$ (причем при УФ воздействии даже более эффективно) [5]. Анализ образовавшихся кристаллитов показывает, что это нитраты и нитриты калия и $\mathrm{KIO}_{3}$. В ИК спектрах проявляются молекулярные колебания диоксида и тетраоксида азота и анионов $\mathrm{NO}_{3}^{-}$. При локализации на поверхности молекулярных форм азота в водных растворах неизбежно образование нитрата и нитрита:

$$
2 \mathrm{NO}_{2} \rightarrow \mathrm{NO}_{3}^{-}+\mathrm{NO}^{+} \text {. }
$$

$\mathrm{NO}^{+}$может обеспечивать вскрытие поверхности кристалла, обеспечивая условия для стабилизации $\mathrm{KNO}_{3}$, а $\mathrm{NO}_{3}^{-}$связываться поверхностью. В итоге имеем

$$
\begin{gathered}
3 \mathrm{NO}_{2}+2 \mathrm{KI}+(1 / 2) \mathrm{O}_{2}=\mathrm{NO}+\mathrm{KNO}_{3}+\mathrm{I}_{2}, \\
\mathrm{NO}+(1 / 2) \mathrm{O}_{2}=\mathrm{NO}_{2}, \\
2 \mathrm{NO}_{2}+2 \mathrm{KI}+\mathrm{O}_{2}=2 \mathrm{KNO}_{3}+\mathrm{I}_{2}, \\
\mathrm{I}_{2}+\mathrm{H}_{2} \mathrm{O}=\mathrm{HOI}+\mathrm{H}^{+}+\mathrm{I}^{-}, \\
3 \mathrm{HOI}=3 \mathrm{H}^{+}+\mathrm{IO}_{3}^{-}+2 \mathrm{I}^{-}, \\
\mathrm{I}_{2}+\mathrm{I}^{-}=\mathrm{I}_{3}^{-} .
\end{gathered}
$$

Эти реакции объясняют, почему в растворах с KI растворение йода идет проще и появляется поглощение, связанное с $\mathrm{I}^{-}, \mathrm{I}_{3}^{-}$и $\mathrm{IO}_{3}^{-}$. Диоксид азота в присутствии кислорода воздуха реагирует с йодидом калия, вызывая образование трийодида. Понятно, что для кристаллического $\mathrm{I}_{2}$ в присутствии диоксида азота и щелочного металла реакция растворения йода идет эффективнее, что и подтверждается экспериментально. Без наличия йодида калия или сорбированного $\mathrm{NO}_{2}$, т. е. анионов $\mathrm{I}^{-}$ и $\mathrm{NO}_{3}^{-}$, растворение $\mathrm{I}_{2}$ в дистиллированной воде крайне слабое. При внесении $100 \mathrm{mg} / \mathrm{I}_{2}$ в дистиллированную воду по истечении недели по суммарному поглощению обнаружено всего $\sim 5 \mathrm{mg} / \mathrm{l}$ йода, а остальной йод так и оставался кристалликом на дне колбы. Для его полного растворения потребовалось внесение в раствор йодида калия существенно превышающей концентрации. При наличии в воде растворителя нитратов (природная вода) при тех же условиях растворяется половина внесенного в раствор йода, т. е. растворимость становится значительно выше.

При нормальной $\mathrm{pH}$ содержание $\mathrm{OH}^{-}$и $\mathrm{H}^{+}$в воде $\sim 10 \mathrm{mg} / \mathrm{l}$. Это приводит к появлению в растворе $\mathrm{I}^{-}$, $\mathrm{IO}_{3}^{-}$(в результате последовательного окисления), часть $\mathrm{I}_{2}$ образует с неионизованной водой комплекс, поглощающий при $460 \mathrm{~nm}$. После появления $\mathrm{I}^{-}$небольшая часть этих ионов при взаимодействии с $\mathrm{I}_{2}$ приводит к созданию трийодид-иона $\mathrm{I}_{3}^{-}$. В балансе только небольшое количество исходного йода может перейти в растворенное 
состояние. Этот процесс наблюдается при растворении йода в дистиллированной воде. При высокой общей минерализации воды за счет содержания в ней солей (в нашем случае $\mathrm{KNO}_{3}$ ) растворимость йода повышается в основном за счет образований ионов $\mathrm{I}^{-}$и $\mathrm{NO}_{3}^{-}$, что и наблюдается в спектре.

В насыщенных растворах йода общее количество $\mathrm{NO}_{3}^{-}$ в растворе велико, поэтому выделение на фоне поглощения нитрат-иона поглощения $\mathrm{I}^{-}$, несомненно присутствующего в растворе, крайне затруднительно. Отнесение полосы $202 \mathrm{~nm}$ не к поглощению комплекса молекулярного йода с водой, а к поглощению нитрат-иона обусловлено еще одним обстоятельством. Молекулярный йод при возбуждении светом короче $499 \mathrm{~nm}$ в принципе уже не может существовать в виде молекулы (в комплексе с разными растворителями молекула может быть чуть стабильнее), поэтому поглощение в области $202 \mathrm{~nm}$ не может принадлежать недиссоциированной молекуле йода.

Присутствие в воде азота в виде нитрат-иона, малый коэффициент молярной экстинкции комплекса йода с растворителем, слабое бесструктурное поглощения $\mathrm{IO}_{3}^{-}$ затрудняют оценку общего содержания йода в водах по спектру поглощения. Даже небольшое поглощение в области спектра $226 \mathrm{~nm}\left(\mathrm{I}^{-}\right)$и 290 и $350 \mathrm{~nm}\left(\mathrm{I}_{3}^{-}\right)$ будет свидетельствовать о высоком содержании йода в воде, так как в виде йодид- и трийодид-иона связывается небольшое количество йода.

Сложное поведение йода в природных и инженерных средах и невысокие концентрации его присутствия стимулируют изучение йодсодержащих систем и развитие методов его корректного определения [22-24].

\section{Конфликт интересов}

Авторы заявляют, что у них нет конфликта интересов.

\section{Список литературы}

[1] Киреев С.В., Шнырев С.Л. Оптические методы детектирования долгоживущих изотопов йода. М.: НИЯУ МИФИ, 2010.

[2] Василенко И.Я., Василенко О.И. // Энергия, экономика, техника, экология. 2003. № 5. С. 57-62.

[3] Bichsel Y., Gunten U. // Anal. Chem. 1999. V. 71. P. 34-38.

[4] Алукер Э.Д., Лучис Д.Ю., Чернов С.А. Электронные возбуждения и радиолюминесценция щелочно-галоидных кристаллов. Рига: Зинатне, 1979. 251 с.

[5] Александров А.Б., Алукер Э.Д., Васильев И.А., Нечаев А.Ф., Чернов С.А. Введение в радиационную физикохимию поверхности щелочно-галоидных кристаллов. Рига: Зинатне, 1989. 244 с.

[6] Грузинщев А.Н., Загороднев В.Н. // ФТТ. 2012. Т. 54. В. 1. C. $110-114$.

[7] Gerstenkorn S., Vergès J., Chevilard J. Atlas du Spectre d'Absorption de la Molecule d'Iode $\left(11000-14000 \mathrm{~cm}^{-1}\right)$. / Ed. by Gerstenkorn S., Luc P., Chevilard J. Orsay: Edition CNRS II, 1982.
[8] Прялкин Б.С., Муратова Н.Г. // Полифункциональные химические материалы и технологии. 2015. Т. 2. С. 165-169.

[9] Киселев В.М., Багров И.В., Стародубщев А.М. // Опт. и спектр. 2018. Т. 124. В. 2. С. 197-201.

[10] Быковский Ю.А., Котковский Г.Е., Кузнещов М.Б., Чистяков А.А. // ЖЭТФ. 1998. Т. 114. В. 1 (7). С. 1.

[11] Refat M.S., El-Didamony A.M., Grabchev I. // Spectrochim. Acta. Part A: Molecular and Biomolecular Spectroscopy. 2007. V. 67. N 1. P. 58.

[12] Киреев С.В., Симановский И.Г., Шнырев С.Л. // Инженерная физика. 2008. № 1. С. 2-28.

[13] Киреев С.В., Симановский И.Г., Шнырев С.Л. // Инженерная физика. 2008. № 2. С. 37-46.

[14] Kireev S.V., Simanovsky I.G., Shnyrev S.L. // Laser Physics. 2009. V. 19. N 9. P. 1939-1949.

[15] Wei Y.J., Liu C.G., Mo L.P. // Guang Pu Xue Yu Guang Pu Fen Xi. 2005. T. 25. № 1. C. $86-88$.

[16] Liu Z.-B., Tian J.-G., Zang W.-P. et al. // Optics Lett. 2004. V. 29. N 10. P. 1099.

[17] Клюбин В.В., Клюбина К.А., Маковецкая К.Н. // Журн. физ. химии. 2017. Т. 91. № 4. С. 620-625; Klyubina V.V., Klyubina K.A., Makovetskaya K.N. // Russian J. Physical A. 2017. V. 91. N 4. P. 620-625.

[18] Aluker N.L., Herrmann M.E., Suzdaltseva Ya.M. // Opt. Spectrosc. 2019. V. 127. N 6. P. 991-996.

[19] Aluker N.L., Lavrentieva A.L., Suzdaltseva Y.M. // Opt. Spectrosc. 2020. V. 128. N 3. P. 422-428.

[20] Palmer D.A., Ramette R.W., Mesmer R.E. // J. Solution Chem. 1984. V. 13. P. 673-683.

[21] Schmidt E., Heiman P. // Anal. Chem. 1997. V. 69. P. 277-284.

[22] Mamane-Gravetz H., Ducoste J.J., Linden K.G. // Proceedings Intern. Ultraviolet Association Conference. Whistler, British Columbia, 2005. P. 10.

[23] Gottardi W. // Archiv der Pharmazie: An Inter. J. Pharmaceutical and Medicinal Chemistry. 1999. V. 332. N 5. P. $151-157$.

[24] Silva R., Oliveira A. // J. Braz. Chem. Soc. 1998. V. 9. P. 171. 